\title{
Avaliação do uso variável das vogais pretônicas: estudos preliminares de crenças e atitudes
}

\section{Evaluation of variable use of pretonic vowels: preliminary studies of beliefs and attitudes}

Anna Carolina da Costa Avelheda ${ }^{1}$, Eliete Figueira Batista da Silveira ${ }^{2}$, Silvia Carolina Gomes de Souza ${ }^{3}$

Doutoranda em Letras Vernáculas (Língua Portuguesa) pela Universidade Federal do Rio de Janeiro, com Bolsa de Auxlilo do CNPq, vinculada e Mudança do Programa de Pós-Graduação em e Mudança, do
Letras Vernáculas.

E-mail: carolavelheda@hotmail.com

Professora Adjunta do Setor de Língua Portuguesa do Departamento de Letras Vernáculas da Universidade Federal do Rio de Janeiro. E-mail: elietesilveira@hotmail.co Portuguesa) pela Lniversidade Federas (Língua Janeiro, com Bolsa de Auxílio da CAPES, vinculad à Linha de Pesquisa Lingua e Sociedade: Variaçâo e Mudança, do Programa de Pós-Graduação em Letras Vernáculas.
RESUMO: A presente pesquisa conjuga os pressupostos da sociolinguística variacionista e a metodologia de análise de crenças e atitudes linguísticas, baseando-se em corpora sociolinguisticamente estratificados de falantes do Rio de Janeiro para analisar o alteamento das vogais médias pretônicas Primeiramente, focalizamos os casos de especialização semântica. Por meio de um questionário fonético-fonológico e de um questionário de percepção, observamos como os usuários da língua produzem os itens cujos sentidos podem influenciar na escolha da variante pretônica. A hipótese é a de que o alteamento tende a ocorrer na expressão de significados menos valorizados (VIEGAS, 1987). No segundo estudo, o teste de atitude compõe-se de três técnicas para observar: (i) na leitura de texto, se o informante realiza o alteamento ao ler determinadas palavras no texto; (ii) na entrevista, a avaliação subjetiva do falante em relação ao fenômeno; e (iii) no questionário, se o julgador é afetado pelo teste de percepção anteriormente realizado. Os resultados de ambos os estudos evidenciam relativa avaliação negativa do uso das variantes alteadas, diferentemente do que mostram os trabalhos que focam exclusivamente os fatores condicionantes.

Palavras-Chave: Sociolinguística; Crenças e atitudes linguísticas; Alteamento; Avaliação.

ABSTRACT: The present research combines the assumptions of Variationist Sociolinguistics and the methodology of analysis of linguistic beliefs and attitudes (LAMBERT, 1967; GOMEZ MOLINA, 1998), based on sociolinguistically stratified corpora of speakers from Rio de Janeiro to analyze the process of raising of pretonic mid vowels. Firstly, we focus on cases of semantic specialization. Through a phonetic-phonological questionnaire and a perception questionnaire, we observes how the users of the language produce the items whose meanings can influence in the choice of the pretonic variant. The hypothesis is that the rise tends to occur in the expression of less valued meanings (VIEGAS, 1987). In the second study, the attitude test is composed of three techniques to observe: (i) in reading text, if the informant performs the raising when reading certain words in the text; (ii) in the interview, the subjective evaluation of the speaker in relation to the phenomenon; and (iii) in the questionnaire, if the judge is affected by the perception test previously performed. The results of both studies show a relative negative evaluation of the use of the high variants, differently from the studies that focus exclusively on the conditioning factors.

KEYwORDS: Sociolinguistics; Linguistic beliefs and attitudes; Raising; Evaluation. 


\section{Introdução}

Orats processo de alteamento pretônico é fundamentalmente caracterizado pela elevação da vogal média, que passa a se realizar por meio de uma vogal alta, atestando-se "a realização alternante de [e $\sim$ i] e [o u]" e a "substituição de um fonema por outro que com ele estabeleceria par opositivo" (AVELHEDA, 2013, p. 30). É muitas vezes explicado a partir do processo de harmonização vocálica, em que há assimilação do traço fonético de altura da vogal presente na sílaba seguinte, como se observa, por exemplo, em $m[i] n \underline{i n} o$ por $m[e] n \underline{i n}$ o e $b[u]$ it to por b[o]nito. No entanto, há casos em que o alteamento demonstra-se controlado pelo processo de redução vocálica, em que há o enfraquecimento da vogal por assimilação de traços consonantais adjacentes, como em [i]mpregada, s[i]nhor, t[u]mate, $b[u]$ neca.

Por constituir um fenômeno em variação na língua portuguesa, é amplamente discutido em termos de fatores condicionantes (WEINREICH; LABOV; HERZOG, 2006), a partir de pesquisas que procuram atestar os aspectos fonético-fonológicos, morfológicos e lexicais que controlam a ocorrência do fenômeno (VIEGAS, 1987; BISOL, 1981; BRANDÃO; CRUZ, 2005; SILVEIRA; TENANI, 2007; AVELHEDA; BATISTA DA SILVEIRA, 2011; AVELHEDA, 2013). No entanto, o problema da avaliação não é comumente considerado em relação ao processo de alteamento, não havendo ainda trabalhos que se dediquem a observar a avaliação subjetiva dos falantes em relação ao fenômeno.

Na tentativa de suprir essa carência e de chamar a atenção para a relevância da implementação dessa metodologia, o presente artigo trata da avaliação subjetiva, por meio da análise de crenças e atitudes linguísticas, tendo por objeto de análise as vogais médias pretônicas, passíveis de alteamento. Nesse sentido, tem por objetivo observar a realização, a percepção e a avaliação $^{1}$ (LABOV, 2008; MACHADO VIEIRA; ESTEVES, 2009; OUSHIRO, 2015) que o usuário da língua faz em relação ao processo. Para tanto, foram propostas duas diferentes vertentes de análise, baseados em vários tipos de testes de atitudes. É importante destacar que, por se tratar de estudos preliminares que norteiam o desenvolvimento de futuras análises de crenças e atitudes linguísticas em termos de alteamento pretônico, aqui ainda não se procede à realização de testes estatísticos, uma vez que o objetivo era avaliar, em função das respostas dos juízes, a avaliação conferida ao processo de alteamento. Os resultados que são aqui obtidos não são compreendidos como unânimes na comunidade como um todo, mas representativos do recorte selecionado (Cf. Seção 3).

A primeira vertente de análise focaliza a especialização semântica a partir de alguns casos que comprovam o pressuposto de Labov (2008, p. 290) de que "os falantes não aceitam de imediato o fato de que duas expressões diferentes 'têm o mesmo significado' e existe uma forte tendência a atribuir diferentes significados a ela". A segunda vertente de análise, por sua vez, focaliza a noção de estigma e observa (a) se os informantes produzem o alteamento das vogais pretônicas, (b) se avaliam o fenômeno sob análise e (c) se, após a avaliação, tendem a controlar mais o alçamento. Fundamenta-se a proposta na afirmação de Viegas (1987) de que a variação entre as vogais médias e as vogais altas em posição pré-acentual, na fala de Belo Horizonte, "traz em si certo estigma social".

${ }^{1}$ Segundo Labov (2008, p. 247), a percepção se dá quando os falantes são capazes de identificar diferenças e similaridades entre variantes: "No caso de fusão total de uma distinção fonológica, os falantes não conseguem ouvir se $x$ é mais próximo de $A$ ou de $B$; mas, onde regras variáveis estão operando e a fusão não se completou, eles exibem êxito parcial". Para Oushiro (2015, p. 32), a avaliação operando e a fusão não se completou, eles exibem êxito parcial". Para Oushiro (2015, p. 32), a avaliação
diz respeito "ao discurso metalinguístico dos falantes sobre variantes, o que constitui um objeto de diz respeito "ao discurso metalinguístico dos falantes sobre variantes, o que constitui um objeto de estudo em si", enquanto a percepção configura-se de "inferências feitas pelos usuários de uma língua ao ouvirem outro falante, que podem ou não ser conscientes e que, portanto, podem não ser objeto de comentário metalinguístico". Aqui, toma-se a percepção como a identificação ou o reconhecimento de diferenças e similaridades, conforme defendido por Labov (2008), enquanto a avaliação compreende
as inferências feitas pelos usuários de língua e, por conseguinte, a sua manifestação. 
Para cumprir com seu objetivo, o presente artigo desenvolve-se em três seções. Na primeira, abordam-se os aspectos teóricos subjacentes aos estudos de crenças e atitudes linguísticas. Na segunda, apresentam-se as orientações metodológicas e os resultados das duas vertentes de análise anteriormente descritas, apresentando-se algumas apreciações críticas. Na terceira, cotejam-se os resultados de cada uma dessas vertentes da análise experimental, tecendo-se comentários a respeito do comportamento dos usuários frente ao alteamento pretônico.

\section{Os estudos de crenças e atitudes linguísticas}

Os estudos de crenças e atitudes linguísticas no âmbito da fonética e da fonologia são ainda muito esparsos no Brasil, restringindo-se quase exclusivamente ao uso dos róticos (BOTASSINI, 2013; DIAS, 2014). Apesar de ser um dos pilares da teoria Sociolinguística Variacionista, o problema da avaliação, amplamente considerado por Labov (2008), por exemplo, em seus estudos na Ilha de Martha's Vineyard e em Lojas de Departamento da Cidade de Nova Iorque, encontra-se relegado na maioria dos estudos, em virtude da dificuldade em se auferir a avaliação subjetiva dos usuários da língua frente a algum fenômeno variável.

Para suprir essa deficiência, o surgimento dos estudos de atitudes linguísticas, na segunda metade da década de sessenta, foi um marco importante, sendo Wallace Lambert responsável pela "preocupação com os aspectos social, ideológico e cultural da linguagem, tornando mais complexos os estudos da diversidade linguística na área da Sociolinguística" (BOTASSINI, 2012, p. 357). Os conceitos de crenças e atitudes assumem uma difícil caracterização, uma vez que há quem os considere equivalentes, mas há os que argumentam em favor da distinção desses aspectos. Para López Morales (1993), é necessário que se distingam os conceitos, uma vez que crenças "podem estar integradas por elementos cognitivos ou afetivos", enquanto atitudes estão dominadas "apenas pelo traço comportamental" e "só podem ser positivas, de aceitação, ou negativas, de rejeição" (BOTASSINI, 2012, p. 358), sendo reguladas pelos grupos sociais de maior prestígio, "os mais altos na escala socioeconômica" (AGUILERA, 2008).

Segundo o autor, atitudes linguísticas são consideradas sob duas abordagens distintas: a mentalista e a comportamentalista. A concepção mentalista caracteriza atitude como um estado de disposição, o qual intervém entre o estímulo que afeta a pessoa e sua resposta a esse estímulo, configurando uma estrutura componencial, constituída pelos elementos afetivo (emoções e sentimentos), cognitivo (percepções, crenças, estereótipos) e comportamental (tendência a manifestar determinada reação com respeito ao objeto). No entanto, sob essa perspectiva, atitudes não seriam diretamente analisáveis por meio dos comportamentos que o falante apresenta. A abordagem comportamentalista, por sua vez, compreende o termo atitude como o comportamento que o falante assume diante de um estímulo, o que dificulta, entretanto, a constituição de um padrão sistemático.

Labov (2008, p. 210-212) classifica, como indicadores, marcadores ou estereótipos, "os diversos elementos envolvidos na mudança linguística segundo o tipo de avaliação social que eles recebem". O fenômeno variável é considerado um indicador quando está abaixo do nível da consciência social e não é reconhecido pelos falantes, ainda que possa haver diferenciação de uso dessas formas correlacionada a idade, região ou classe social. Quando "a mudança sonora [...] alcançou os limites de sua expansão", tornando-se uma norma na comunidade, passa a ser considerado marcador, visto que apresenta algum grau de consciência, demonstrando estratificação social e estilística, e os falantes produzem respostas regulares quando se aplicam testes de reação subjetiva. Por último, o fenômeno passa a estereótipo 
quando se torna sujeito a comentários e suscetível à correção, constituindo "formas socialmente marcadas, rotuladas enfaticamente pela sociedade".

Com o objetivo de analisar as crenças e as atitudes dos usuários da língua, são propostos testes de atitude, que podem ser construídos a partir de dois métodos: (a) direto, no qual o falante tem consciência de que suas impressões estão sendo avaliadas; e (b) indireto, no qual o respondente não está consciente de que suas atitudes estão sob avaliação. De acordo com Abraçado; Kenedy (2014), há quatro exemplos de testes que podem ser utilizados: (a) reação subjetiva, em que o respondente emite juízos de valor em relação à personalidade das pessoas; (b) extração familiar, em que o respondente é levado a identificar origem e classe social, por exemplo; (c) autoavaliação, em que é solicitado que o respondente reconheça qual é a sua maneira própria de falar; e (d) insegurança linguística, em que é levado a indicar a forma correta entre duas ou mais opções e, em seguida, a apontar a que realmente usa. Quanto às técnicas, Machado Vieira ; Esteves (2009) afirmam que diversas podem ser utilizadas: (a) questionário aberto, que permite que o respondente disserte livremente sobre determinado assunto; (b) questionário fechado, que apresenta perguntas de múltipla escolha; (c) entrevistas, em que o pesquisador faz perguntas e registra manualmente ou em mídia digital as respostas obtidas; (d) leitura, em que o informante lê um texto e o pesquisador observa seu comportamento.

\section{Análises experimentais}

Conforme se descreveu anteriormente, a presente pesquisa compõe-se de duas vertentes de análise: a primeira focaliza a especialização semântica, compreendida como um processo que "consiste em reservar cada variante para a expressão de um sentido particular" (AVELHEDA, 2013, p. 54); a segunda, por sua vez, focaliza a noção de estigma, que indica que atitudes e posicionamentos em relação à língua refletem atitudes e posicionamentos em relação a seus usuários. Assim sendo, as duas análises experimentais propostas serão apresentadas separadamente.

\subsection{Alteamento pretônico e especialização semântica}

Viegas (1987) encontrou evidências de uma atuação lexical relacionada ao alteamento, que se manifesta pelo fato de que "o item alçado é aquele cujo uso normalmente é feito em situações mais familiares ou menos prestigiadas" (VIEGAS, 2001).

Nas formas em que a vogal média está em oposição distintiva em relação à vogal alta, aqueles itens que têm um uso considerado menos prestigiado socialmente alçam ( $p[u] r c ̧ \tilde{a} o$, com significado de 'muita quantidade', traz o rótulo de brasileirismo em dicionários) e aqueles cujo uso é socialmente considerado mais prestigiado não alçam (Peru é inclusive escrito com letra maiúscula e porção é usado, normalmente, em restaurantes) (VIEGAS, 2001, p. 18-19).

Compreende-se que a especialização semântica constitui um processo variável que "consiste em reservar cada variante para a expressão de um sentido particular", o que vai ao encontro da ideia de que "algumas variantes podem não ter a mesma significação e o uso de uma ou de outra forma fica condicionado à semântica" (LABOV, 2008). Como variável, pode se manifestar ou deixar de se manifestar a depender da comunidade estudada e do usuário da língua que está sendo avaliado, uma vez que se baseia na intimidade ${ }^{2}$ do informante com o item, no conhecimento de mundo que o informante detém. A seleção dos vocábulos experimentais fundamentou-se

2 Destaque-se que a intimidade é compreendida como um traço que pode ser individual e que está relacionado à frequência de uso do item vocabular, ou seja determina do informante pode apresentar relacionado a frequência de uso do item vocabular, ou seja, determinado informante pode apresentar uma intimidade maior com um vocábulo experimental, devido à frequência em que o utiliza, enquanto outro inornante pode não apresentar intimidade com o mesmo item. Assim, pode-se compreende com o item 'porção' que se diferenciará da intimidade que tem o cliente que lá chega para almoçar. 
em alguns casos de especialização semântica tradicionalmente apontados na literatura linguística (VIEGAS, 1987; OLIVEIRA, 1991; VIEGAS, 2001) e outros casos especificamente encontrados por Avelheda (2013). Sendo assim, cabe especificar os significados (Quadro 1) que comumente fazem parte de um contexto informal de uso, podendo ser veiculados através da variante alteada, e aqueles que constituem um contexto mais formal, para os quais se prefere a variante médio-alta ${ }^{3}$.

Quadro 1 - Significados dos Vocábulos Experimentais

\begin{tabular}{|l|l|l|}
\hline Item & $\begin{array}{l}\text { Significado Formal / } \\
\text { Valorizado Socialmente }\end{array}$ & $\begin{array}{l}\text { Significado Informal / } \\
\text { Desvalorizado Socialmente }\end{array}$ \\
\hline Porção & Quantidade menor que o todo. & Grande quantidade de algo. \\
\hline Peru & Ave / País. & Órgão Genital. \\
\hline Concerto / Conserto & Música Clássica. & Reparo, Ajuste. \\
\hline Seguro & Proteção. & Confiança. \\
\hline Cobertura & Terraço. & Calda. \\
\hline Senhor & Deus. & Idoso. \\
\hline Português & Língua Materna. & Indivíduo Lusitano. \\
\hline Perua & Kombi. & Mulher espalhafatosa. \\
\hline Fogão & Botafogo, Glorioso. & Aparelho Doméstico. \\
\hline Serviço & Trabalho, Profissão. & Funcionalismo Público. \\
\hline Sentido & Ordem Militar / Direção. & Significado / Chateado. \\
\hline Segurança & Segurança Pública. & Segurança Pessoal. \\
\hline
\end{tabular}

3 Avelheda (2013, p. 211-214), em Dissertação intitulada O Alteamento das Vogais Médias Pretônicas no Município de Nova Iguaçu, identificou alguns casos de especialização semântica: (i) quando o item
serviço "apresenta um significado mais genérico, como o de trabalho, o não alteamento é categórico", mas, quando "apresenta o significado mais específico, voltado para o funcionalismo público", então se encontra "uma variação entre o alteamento e o não alteamento"; (ii) quando o item segurança "remete ao significado de estabilidade profissional, assim como quando remete à profissão de segurança pessoal, o alteamento se processa nos itens", mas, quando o item segurança "se refere a alguma função específica de sua profissão, o informante prefere a variante média à alteada"; (iii) no caso do vocábulo sentido, estudos de Oliveira (1991) e de Viegas (2001) revelam que "quando se refere ao significado de uma palavra, o vocábulo tende a se realizar pela variante alteada", mas, quando "se refere a um imperativo
O presente experimento se baseia na hipótese de que o alteamento tende a ocorrer "quando o significado veiculado pelo item é menos prestigiado socialmente", ao passo que "a expressão de significados mais valorizados se dá sistematicamente pela manutenção da vogal média" (AVELHEDA, 2013, p. 217). Assim, pressupõe-se que os respondentes selecionarão e produzirão formas alteadas quando perceberem significados social e contextualmente mais pejorativos, desprestigiados, jocosos ou irônicos.

Em se tratando de fenômenos linguísticos, sobretudo daqueles que não despertam estigmatização social, sabe-se que a diferença entre o que o usuário da língua diz realizar e o que ele efetivamente realiza é bastante relevante ${ }^{4}$ (LABOV, 2008; OUSHIRO, 2015). Assim, percebe-se que o estudo da especialização semântica em termos de alteamento pretônico é beneficiado pelo trabalho em etapas para a verificação da diferença entre o que o informante responde quando se formula uma questão com vistas a detectar a produção fonética e o que ele diz perceber como melhor alternativa, já que "aquilo que as pessoas dizem e o modo como reagem a certas variantes podem não coincidir" (OUSHIRO, 2015, p. 32). Portanto, para atingir o objetivo delimitado para o presente estudo, elaboraram-se dois experimentos: um questionário fonético-fonológico e um questionário de percepção idealizado para este estudo.

militar, tende a se manifestar a variante média", assim como expressa a noção de direção; (iv) quando o item português "se refere à língua-mãe do povo brasileiro, o não alteamento é categórico", mas, "quando se refere ao povo ou às características de Portugal, geralmente tratados de maneira jocosa e menos depreciativa, encontra-se uma variação entre o alteamento e o não alteamento", que também se pode explicar por uma generalização de um estereótipo "de sua norma de fala", já que procedem ao alteamento pretônico em sua norma e isso os caracteriza perante os brasileiros, que prioritariamente conservam a vogal média em posição pretônica. 4 Em Nova Iorque, Labov (2008) atestou que os informantes diziam usar mais as formas de prestígio do que de fato faziam no cotidiano, apresentando um grau de "superestima linguística" sensivelmente elevado (FREITAG, 2015: 36). 
O questionário fonético-fonológico ${ }^{5}$ visa a identificar como os usuários da língua produzem os itens cujos sentidos poderiam influenciar na escolha da variante alteada ou da variante médio-alta. Compõe-se de setenta questões, sendo vinte e seis questões-estímulo e quarenta e quatro distratoras, distribuídas entre si de forma aleatória, de modo a não permitir que respondentes mais perspicazes detectem o que se pretende analisar ou observem alguma sistematicidade. 0 questionário de percepção ${ }^{6}$, por sua vez, visa a obter a avaliação dos respondentes a respeito das alternativas propostas para cada questão-estímulo. Foram elaboradas quarenta e oito questões, sendo dezoito questões-estímulo e trinta distratoras, distribuídas em quatro subconjuntos de dez questões, de modo que nem todos os informantes precisem avaliar os mesmos enunciados. Cada subconjunto abarca quatro questões-estímulo e seis questões distratoras, com exceção do quarto subconjunto, que apresenta seis questões-estímulo e apenas quatro distratoras.

Os questionários foram aplicados a um universo de respondentes composto de dezoito informantes naturais do Rio de Janeiro, selecionados com base em estratificação sociolinguística, sendo um homem e uma mulher de cada faixa etária (15 a 35 anos; 36 a 55 anos; 56 a 75 anos), distribuídos

\footnotetext{
Exemplos de questões-estímulo do Questionário Fonético-Fonológico: 1) Como se chama a quantidade de batatas fritas ou salgados servida em um bar? Porção. 2) Qual é o nome do país cujos habitantes são chamados peruanos? Peru. 3) Como se chama a apresentação de música clássica? Concerto. 4) Como se chama a ave assada, geralmente, para a Ceia de Natal? Peru. 5) Quando o carro está com defeito, nós o levamos ao __ Conserto. 6) Como se diz quando, em determinado lugar, tem muita gente? Porção de gente.

${ }^{6}$ Exemplo de questão-estímulo do Questionário de Percepção Linguística:

1) Imagine que você está em um Restaurante e gostaria de pedir ao Garçom que lhe trouxesse batatas fritas. Como você faria seu pedido?

a) “- Garçom, por favor: uma porção de batatas fritas".

b) “- Garção, por obséquio: queira trazer-me um lote de tubérculos tesos".

c) "- Garçom, por favor: uma p[u]rção de batatas fritas".

d) "- Garçom, tenha a benevolência de trazer-me aquele quinhão de batateiros duros"

e) Nenhuma das alternativas anteriores.
}

pelos níveis fundamental, médio e superior de escolaridade, totalizando dezoito informantes ${ }^{7}$ que não estivessem expostos ou motivados a uma consciência científica a respeito de fenômenos linguísticos.

\subsubsection{Questionário fonético-fonológico}

Entre os vinte e seis itens cujos sentidos poderiam influenciar na escolha da variante alteada ou da variante médio-alta, retirados de Viegas (1987) e Avelheda (2013), cinco jamais foram reconhecidos pelos respondentes, em virtude de configurarem (a) uma designação que não corresponde à utilizada na região pesquisada (perua, para referir-se a uma Kombi, é designação mais típica do Estado de São Paulo, o que chegou a ser observado por alguns respondentes); (b) uma expressão que parece não se aplicar à situação comunicativa proposta (porção, para referir-se a uma excessiva quantidade, não é utilizada em relação a pessoas e parece estar em desuso na fala da maioria dos respondentes, que preferem opções como tumulto, montoeira e multidão, sendo esta a que, segundo um dos respondentes, apresenta a informação mais precisa); e (c) opções não-preferenciais para a situação descrita, como sentido (para referir-se a magoado ou a significado) e serviço (para referir-se ao funcionalismo público), que foram recorrentemente substituídos por outras designações, como, respectivamente, triste, aborrecido e decepcionado; explicação, significado e definição; trabalho, emprego e funcionalismo.

Há três itens, ainda, que, embora produzidos por alguns respondentes, não o foram com tamanha facilidade e demandaram maior tempo de

7 Apesar de se tratar de um número pequeno de informantes, considere-se que este estudo é preliminar e é fruto de um Trabalho de Conclusão de Curso (TCC) de Pós-Graduação. Ademais, Eduardo Kenedy, em aula ministrada aos alunos deste Curso, mencionou que uma análise experimental poderia ser realizada com a participação de vinte respondentes, o que também se observa em Abraçado; Kenedy (2014), cujos estudos foram realizados com uma média de vinte participantes para cada experimento promovido. 
raciocínio, bem como algumas reformulações da questão inicialmente proposta: seguro, quando se referia a alguém que está confiante do que faz, foi produzido por dois respondentes com alteamento pretônico e por um respondente com a variante médio-alta; o item sentido, quando se referia à direção que alguém deveria seguir, foi produzido por três respondentes com alteamento pretônico, os quais o realizaram por meio de vogal médio-alta quando designava a ordem militar que pede postura e atenção do pelotão, configurando a especialização semântica que se deseja observar.

Por fim, o item serviço, quando referente ao trabalho que alguém realiza na profissão que exerce, foi produzido por seis respondentes com vogal médio-alta e por dois respondentes com alteamento pretônico, mas a contraparte alteada para referir-se ao serviço público não foi atestada, conforme já anteriormente explicitado. No caso de serviço para referir o trabalho que alguém realiza na profissão que exerce, é interessante notar que um respondente da segunda faixa etária (51 Anos), detentor de nível fundamental de escolaridade, procede a uma especialização bastante interessante, referindo-se ao trabalho do gari através da variante alteada, mas ao seu utiliza por meio da variante médio-alta.

Com base nos resultados obtidos a partir do questionário fonéticofonológico, pôde-se observar que a variação ocorreu, pelo menos em relação ao item português, justamente na designação tida como menos valorizada socialmente: o alteamento só se processou (2/18 oc.) na designação do indivíduo lusitano, enquanto a designação da língua materna se realizou categoricamente por meio de variante médio-alta (18oc.), o que demonstra que se atribuem valor e reconhecimento à língua pátria, o que se reflete mesmo na maneira de a ela se referir. Aponta, ainda, que o tom jocoso, que poderia explicar a ocorrência do alteamento em relação ao indivíduo lusitano, parece não encontrar espaço para se manifestar nesse tipo de análise experimental, uma vez que a situação de perguntas e respostas de um questionário fonético-fonológico (cf. Figura 1) pode inibir um comportamento mais informal.

Nos itens serviço e segurança, a situação se apresentou de maneira diferente do resultado encontrado em Avelheda (2013): (a) em relação ao vocábulo serviço, o alteamento não se processou quando o item se referia ao funcionalismo público, mas se realizou (2/8 oc.) quando se referia ao trabalho; (b) em relação ao vocábulo segurança, o alteamento se processou (10/15 oc.) quando se referia à segurança pública, mas foi menos frequente $(4 / 14$ oc.) quando remetia ao profissional encarregado de vigia, de segurança pessoal. Também no caso de sentido, o alteamento se processou exclusivamente ao referir-se à direção em que se deve seguir, mas a designação de significado não foi obtida pelos respondentes através deste item.

No primeiro caso (serviço), deve-se ressaltar que nem todos os informantes chegaram à noção de funcionalismo público (2 Respostas/18 Respondentes) e os que a reconheceram por meio da pergunta formulada precisaram de tempo mais prolongado para o raciocínio. No segundo caso, observa-se que as perguntas formuladas para obtenção do vocábulo segurança não permitiram que os respondentes procedessem a uma diferenciação de significado semelhante ao que se observou em Avelheda (2013), que identificou que o uso da variante alteada se relacionava à segurança pública e que o uso da variante médio-alta se relacionava à segurança pessoal. Por fim, também nem todos os respondentes chegaram à noção de direção (5 Respostas/18 Respondentes), mas os que o fizeram foram mais espontâneos, o que justifica a ocorrência de três casos de alteamento, diferentemente do que se observou em Avelheda (2013).

Em relação aos demais pares, provenientes de observações e constatações empíricas, percebe-se que o alteamento se manifesta com maior frequência justamente nos sentidos mais informais ou menos valorizados socialmente: (a) cobertura se manifesta pela vogal alta quando designa a calda que se 
coloca por cima de um bolo (8/17 oc.), ao passo que a preferência pela vogal médio-alta acontece quando se refere ao terraço de pessoas mais ricas (13/14 oc.); (b) conserto se realiza pela variante alta quando se refere ao reparo que se faz em algo que apresenta defeito ( $7 / 11$ oc.), mas concerto, que se refere a uma apresentação de música clássica, se realiza prioritariamente pela vogal médio-alta (13/14 oc.); (c) Senhor apresenta a variante alteada quando se refere a idosos ( $3 / 15$ oc.), mas, ao se referir a Deus, se realiza exclusivamente pela variante média (16/16 oc.); e (d) fogão se realiza quase categoricamente pela variante alta (17/18 oc.) quando se refere ao aparelho doméstico que se utiliza para cozinhar, mas a contraparte referente ao time que tem por símbolo uma estrela solitária se realiza categoricamente pela variante médio-alta (14/14 oc.).

Por outro lado, o item seguro ultrapassa as expectativas ao se realizar primordialmente por vogal alta quando se refere à proteção veicular (12/18 oc.) e manifestar também a vogal alta quando remete à confiança que alguém tem em si mesmo ou no próximo ( $2 / 3$ oc.). No entanto, tal desvio das estimativas pode se justificar pela expansão que atualmente se vem percebendo nas categorias de seguro de proteção para bens materiais: outrora, apenas imóveis e automóveis eram objeto de investimento das seguradoras; atualmente, quaisquer bens materiais podem ser segurados, tais como celulares ou computadores. Já no sentido de confiança que se devota a alguém, percebe-se que foi raramente acessado pelos respondentes, de modo que aqueles que o reconheceram deixaram manifestar-se a pronúncia mais usual.

\subsubsection{Questionário de percepção}

Nesta etapa da pesquisa, cabem destacar alguns comportamentos interessantes dos respondentes frente às questões-estímulo. Enquanto houve vários respondentes que declararam não perceber a diferença entre as alternativas que apresentavam a variante alteada e as que apresentavam a variante não alteada, procedendo à marcação das duas opções para expressão de ambos os significados, também houve aqueles que declararam ter percebido que, em algumas questões, havia alternativas que diferiam exclusivamente pela realização variável da vogal pretônica. Houve ainda aqueles que, para além de terem percebido uma realização divergente da vogal pretônica nas questões experimentais, declararam que estava errada a pronúncia de palavras como português e serviço, quaisquer que fossem os significados veiculados, por meio da vogal alteada, os quais, obviamente, não procederam à marcação da variante alteada em nenhuma questão, em virtude da pressão normativa que parecia atuar.

Em relação ao item peru, dois dos respondentes selecionaram a variante médio-alta para designar tanto a ave assada para a ceia de Natal quanto o país cujos habitantes são chamados peruanos. É interessante observar que os outros dois respondentes, ainda que tenham igualmente selecionado a opção com vogal média para referir-se ao país, selecionaram, em relação à ave assada para a ceia de Natal, a opção "nenhuma das alternativas anteriores", alegando que a opção preferencial, com a vogal médio-alta, trazia a expressão "minha mãe" e que, uma vez que o enunciado informava que locutora e interlocutora eram irmãs, o ideal seria que se dissesse "nossa mãe" ou "mamãe". Acredita-se que, quando se quer referir à ave assada para a ceia de Natal, o alteamento não ocorra para não permitir qualquer referência ao nome por que é popularmente conhecido o órgão genital masculino.

Para o item porção, dois informantes declararam não utilizar "uma porção de" para se referirem a pessoas, preferindo substituí-la por expressões que indiquem que "o local está lotado", "cheio de gente" ou que "há ali uma multidão", sendo esta a que vai mais além no que se refere à lotação do local. Os demais informantes souberam reconhecê-la e disseram utilizá-la com 
alguma frequência, sendo que um dos respondentes selecionou a variante médio-alta, enquanto outro respondente selecionou a variante alta para a noção de intensidade (cf. Quadro 1). No que diz respeito à expressão utilizada em restaurantes para referir-se à quantidade específica de algum alimento, todos os respondentes selecionaram a variante médio-alta, sendo que um dos informantes selecionou as duas variantes, declarando não ter reconhecido nenhuma diferença entre as duas opções.

Em relação ao item segurança, um dos respondentes não procedeu ao alteamento na expressão de nenhum dos significados (segurança pública versus segurança pessoal), avaliando, como melhor alternativa para ambos os significados, a variante não alteada; outro respondente, por sua vez, procedeu à elevação pretônica para ambos os significados, avaliando, como melhor alternativa, a variante alteada. Os demais respondentes marcaram ambas as opções, afirmando não terem percebido diferenças entre as variantes alteada e não alteada.

Quanto ao item fogão, dois respondentes indicaram as variantes alteada e não alteada como formas possíveis de expressão do significado referente ao aparelho doméstico. No entanto, um deles disse utilizar apenas a variante não alteada e, quando se referia ao time, corroborou seu posicionamento ao dizer não ter marcado a opção não alteada por acreditar que se referiria ao aparelho doméstico. Também os outros respondentes disseram utilizar apenas a variante não alteada para expressar o significado referente ao aparelho doméstico. Quanto à referência ao time carioca, os respondentes avaliaram como melhor alternativa a frase "- Botafogo é o time menos ruim", o que não auxilia na análise do objeto experimental e provavelmente se justifica por serem torcedores de outro time e não quererem "dar o braço a torcer" ou "trair o time a que devotam sua confiança".

No que diz respeito ao vocábulo experimental serviço para designar $o$ trabalho realizado na profissão que se exerce, dois respondentes avaliaram como equivalentes as opções com as variantes alteada e não alteada, afirmando serem a mesma resposta e não percebendo a diferença fonética. Os demais respondentes avaliaram como melhor alternativa a variante não alteada. Quanto à referência ao funcionalismo público, os respondentes que não reconheceram diferença entre as opções, para expressão do significado de trabalho, permaneceram sem perceber as variantes alteada e não alteada, procedendo à marcação de ambas as alternativas. Entre os respondentes que haviam selecionado apenas a variante médio-alta, para designar o trabalho, um selecionou a variante alteada para designar o funcionalismo público, enquanto o outro selecionou novamente a variante médio-alta.

Em relação ao item português, para referir-se a indivíduos lusitanos, um dos respondentes selecionou a opção "nenhuma das alternativas anteriores", deixando-se levar por questões de ordem pessoal e pragmática. Entre os demais respondentes, houve variação entre as alternativas selecionadas: um respondente selecionou a variante alteada, outro selecionou a variante médioalta e o terceiro, por fim, talvez para se esquivar das variantes experimentais que lhe pareceram semelhantes, selecionou a opção que não incluía o item experimental e que continha a afirmação de que "- 0 dono da Padaria tem uma bela bigodelha". No que diz respeito à referência ao Português como língua materna, dois respondentes selecionaram as alternativas que continham a variante alteada e a variante não alteada, alegando não terem percebido diferenças entre elas. Os demais respondentes selecionaram a variante médio-alta, sendo que um deles selecionou a variante alteada, mas depois declarou ter se confundido com as alternativas e ter desejado marcar efetivamente a variante médio-alta.

O item perua, no que tange à designação do veículo utilizado como transporte complementar no Rio de Janeiro, foi expresso por dois respondentes com a variante médio-alta, os quais ressaltaram que tal designação é mais 
comum entre moradores de São Paulo. O terceiro respondente assinalou a variante alteada, ao passo que os demais selecionaram a opção que correspondia à frase "- A Caminhonete rebentou na senda", afirmando que é o nome que mais se aproxima daquele pelo qual é chamado o veículo. A última respondente, por sua vez, selecionou "nenhuma das alternativas anteriores", afirmando que não conhece aquele veículo pelos nomes apresentados na questão.

No que tange à designação dirigida à mulher espalhafatosa, o mesmo respondente que havia selecionado a variante médio-alta para a expressão do significado de Kombi (perua) procedeu à especialização semântica, selecionando a variante alteada para a expressão deste significado menos valorizado socialmente, assim como o fez outro respondente. Houve também um caso inverso de especialização semântica, que ocorreu no sentido oposto ao esperado: o respondente que havia selecionado a variante alteada para expressar o significado do veículo usado como transporte complementar selecionou a variante médio-alta para se referir à mulher espalhafatosa. Dentre os respondentes, duas mulheres selecionaram a variante médio-alta, o que se pode justificar por uma tentativa de não desvalorizar o grupo a que socialmente pertencem, embora não partilhem da característica de serem espalhafatosas como a mulher que era referida no objeto experimental. Por fim, o último respondente afirmou que não utilizaria a expressão, apenas afirmando que a mulher "queria chamar a atenção".

Por fim, no que diz respeito ao item sentido, que englobava quatro significados distintos, observa-se que, para referir o significado de uma palavra, apenas um respondente selecionou a variante alteada, ainda que tenha também selecionado a alternativa que correspondia à frase "- O dicionário é um livreto que traz o significado das palavras". Os demais respondentes selecionaram (i) ou a variante médio-alta ou (ii) ou a alternativa anteriormente mencionada, que continha a frase “- 0 dicionário é um livreto que traz o significado das palavras". No que tange à designação de alguém que está chateado com o que lhe fez outrem, observa-se que apenas um respondente selecionou a variante alteada, procedendo à especialização semântica, ao passo que os demais informantes selecionaram (i) "nenhuma das alternativas anteriores", afirmando que prefeririam utilizar a expressão "estar decepcionado", no lugar de "estar sentido"; (ii) tanto a variante médioalta quanto a variante alta, afirmando não terem percebido diferença entre as opções; ou (iii) a variante não alteada.

No que se refere à direção que se deve seguir, três respondentes selecionaram a variante não alteada, ao passo que os demais respondentes selecionaram (i) a variante alteada; (ii) a alternativa que continha a frase que dirigia o interlocutor a Nova Iguaçu, não contribuindo para a análise por não conter o vocábulo experimental; ou (iii) "nenhuma das alternativas anteriores", afirmando não saber indicar a direção correta. Por fim, no que se refere à ordem militar (- Sentido!), a seleção da variante não alteada foi categórica, o que corrobora a hipótese de que, em ambientes de formalidade extrema, como o que se supõe ser o quartel, não há espaço para o alteamento pretônico, ainda que se trate de um imperativo usual no contexto.

Portanto, o que se observa é que o alteamento pretônico é efetivamente relacionado (i) à intimidade do respondente com o item, o que faz com que itens que ocorrem na fala cotidiana sejam mais frequentemente alteados (cobertura - a calda que se coloca sobre um bolo; conserto - reparo; seguro - proteção veicular) do que itens que ocorrem em contexto mais específico (porção - quantidade pré-determinada de algum petisco, usado somente em restaurantes e bares; sentido - imperativo militar); e (ii) à valoração que os informantes atribuem aos significados desses itens, de modo que os sentidos socialmente mais valorizados tendem a se expressar pela variante médio- 
alta (o país chama-se Peru e a média pretônica jamais é alteada, assim como não há alteamento para referir-se ao Senhor Deus e ao Concerto de música clássica), enquanto os significados menos valorizados socialmente tendem a se expressar pela variante alteada (fogão - aparelho doméstico; segurança - Secretaria do Estado).

\subsection{Alteamento pretônico e avaliação social}

Com o propósito de observar crenças e atitudes dos falantes em relação ao alteamento das médias pretônicas, foram entrevistados 24 informantes: (i) três mulheres e três homens da primeira faixa etária (20 a 46), detentores de ensino médio; (ii) três mulheres e três homens da segunda faixa etária (46 em diante), com ensino médio; (iii) três mulheres e três homens da primeira faixa etária, com ensino superior completo ou incompleto; (iv) três mulheres e três homens da segunda faixa etária (46 em diante), com ensino superior completo ou incompleto. A estratificação do grupo de informantes permite observar se a faixa etária, o gênero e a escolaridade interferem na realização e na opinião dos informantes.

As hipóteses que norteiam a pesquisa são as de que as pessoas, apesar de realizarem o alteamento das vogais médias pretônicas, conforme indicam vários estudos referentes ao fenômeno, avaliam negativamente o indivíduo que o realiza. A partir disso, desenvolveu-se um teste de atitudes composto por três técnicas: (i) leitura; (ii) entrevistas com áudios; e (iii) questionário fonético-fonológico desenvolvido pelo Projeto Atlas Linguístico do Brasil (ALiB). O registro se realizou por meio de gravador digital.

\subsubsection{Leitura dirigida}

A leitura dirigida do texto objetiva verificar se o informante realiza o alteamento das vogais médias pretônicas quando o lê. O texto apresenta 60 palavras com /e/ pretônico e 49 palavras com /o/pretônico. O texto foi entregue ao informante logo no princípio da entrevista, pois o objetivo era analisar sua fala, antes de que tivesse consciência do objeto de estudo.

Levantaram-se 1380 ocorrências de vogais médias anteriores e 1176 ocorrências de vogais posteriores na leitura do texto. $\mathrm{O}$ alteamento ocorreu, considerando-se a leitura de todos os informantes, 545 vezes nas vogais médias anteriores e 249 vezes nas médias posteriores. Portanto, confirmouse a hipótese de que os informantes produzem o alçamento das médias pretônicas mesmo quando leem o texto, apesar de se tratar de uma situação mais monitorada, em que teoricamente o alteamento devesse ser inibido, ao contrário de sua ocorrência licenciada na "fala natural".

\subsubsection{Entrevista}

Nesta segunda etapa, foram feitas quatorze perguntas a cada entrevistado: oito perguntas são distratoras e seis referem-se ao alteamento. Antes das perguntas, há dois áudios de um mesmo trecho submetidos aos respondentes: no primeiro, as vogais encontram-se alteadas; no outro, as pretônicas se realizam pela variante médio-alta. As perguntas sobre o processo de alteamento tinham como principal objetivo observar se o respondente (i) percebe o alteamento nas construções; (ii) atribui a ocorrência do alçamento a um grupo específico de usuários da língua (faixa etária, gênero, escolaridade, classe social); (iii) relaciona o alteamento ao grau de formalidade da situação comunicativa; (iv) apresenta uma avaliação negativa quando as vogais se realizam pela variante alteada.

O teste aconteceu da seguinte forma: em primeiro lugar, expõem-se os áudios aos respondentes; em seguida, apresentam-se as perguntas. Destaque-se que se expõem aqui os objetivos relacionados às perguntas, bem como se analisam as respostas de acordo com o gênero, a faixa etária e o grau de escolaridade do informante. 
Áudio 1:

A c $[\mathrm{u}]$ stureira cortou o $\mathrm{t}[\mathrm{i}]$ cido da m[i]nina no d[u]mingo, [i]nquanto seu [i]sposo $\mathrm{J}[\mathrm{u}]$ ão $\mathrm{c}[\mathrm{u}] \mathrm{ns}[\mathrm{i}] \mathrm{rtava}$ a $\mathrm{t}[\mathrm{u}]$ rneira e sua filha $\mathrm{M}[\mathrm{i}]$ lissa brincava no [i]st[u]fado com uma $\mathrm{b}[\mathrm{u}]$ neca.
Áudio 2:

A c[o]stureira cortou o t $[\mathrm{e}]$ cido da m[e]nina no d[o]mingo, [e]nquanto seu [e]sposo $\mathrm{J}[\mathrm{o}]$ ão c[o]ns[e]rtava a t[o]rneira e sua filha $\mathrm{M}[\mathrm{e}]$ lissa brincava no [e]st[o]fado com uma b[o]neca.

- Pergunta 1: Você/o(a) senhor(a) acha que existe alguma diferença entre o primeiro áudio e o segundo áudio? Se o informante perceber essa diferença, perguntar o que ele observou.

- ОвјETivo: Verificar se o informante percebeu ou não o alteamento das vogais no primeiro áudio.

Em um total de 24 pessoas, onze mulheres (92\%) perceberam o alteamento e apenas cinco homens (42\%) o identificaram. Além disso, sete homens (58\%) e apenas uma mulher (8\%) não perceberam o alçamento. Oito informantes (67\%) da primeira faixa etária (20 - 46 anos) e da segunda faixa etária ( 46 anos em diante) perceberam o alteamento. Já quatro informantes (33\%) das duas faixas etárias não perceberam o alçamento no primeiro áudio. Em relação à escolaridade, oito informantes (67\%) do ensino médio e do ensino superior não perceberam o alteamento. Portanto, a partir do primeiro teste de percepção deste experimento, observa-se que: (a) em relação ao gênero, as mulheres que participaram do experimento foram mais sensíveis à variante alteada do que os homens; (b) a escolaridade e a faixa etária não interferiram na percepção do alçamento. Abaixo, apresentam-se alguns exemplos de percepção:

(1) "Tem diferença. Eu percebi mais foi que na costureira que no primeiro ela falava c[u]stureira, fala mais pro [u] do que pro [o] e M[e]lissa por $\mathrm{M}[\mathrm{i}] \mathrm{lissa}$. Essas duas deu para perceber bem" (Masculino).

(2) "Percebi que no áudio tem uma linguagem mais regionalizada quando ela

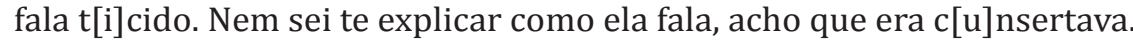
No segundo, eu acho que ela pronunciou o som normal da palavra. A palavra seria $\mathrm{t}[\mathrm{e}] \mathrm{cido}, \mathrm{c}[\mathrm{o}] \mathrm{nsertava}$. Tem outra palavra: [i]stufado, que falou no primeiro; no segundo, [e]stofado" (Faixa 1).

(3) “O segundo áudio é correto, corretíssimo; o outro botou [u] no lugar do [o]: c [u]stureira" (Ensino Superior).

- Pergunta 2: Se você/o(a) senhor(a) fosse falar essa frase, falaria como a primeira opção, a segunda opção ou utilizaria algumas palavras da primeira e outras da segunda?

- OвJETIvo: Verificar a insegurança linguística. O informante é levado a indicar a forma "correta" entre duas ou mais e, em seguida, a apontar a que realmente usa. Ao pedir que o informante lesse a frase, buscou-se observar se havia uma contradição entre o que o informante dizia realizar e o que realmente realizava (LABOV, 2008; OUSHIRO, 2015). Além disso, buscou-se verificar se o informante demonstraria algum preconceito em relação ao alçamento: (i) se o informante não realiza a frase com alteamento, entende-se que acha que a forma adequada para produzir a frase é a sem alteamento; (ii) se ele utiliza toda a frase com alteamento, entende-se que talvez sequer perceba a variação; (iii) se afirma que realiza e produz, na leitura do trecho, as palavras alteadas com e sem alteamento, observa-se que o informante reconhece a possibilidade de as palavras serem realizadas de diferentes formas.

Ao analisar o resultado para essa pergunta, verifica-se que são as mulheres e os informantes do ensino médio que parecem realizar uma avaliação negativa quanto ao uso da variante alteada. Do total de onze mulheres que perceberam o alteamento, oito (67\%) afirmaram que falam 
como o áudio 2 (não alteado), três mulheres (25\%) disseram que falam algumas palavras como no primeiro áudio (alteado) e outras, como o segundo, e apenas uma mulher (8\%) não percebeu o alçamento. Entre os homens, sete (58\%) não perceberam o alteamento, cinco (33\%) afirmaram que falam como no segundo áudio (não alteado) e apenas um (9\%) disse que utilizaria os dois modos de falar.

No que diz respeito à faixa etária, não se verificaram diferenças de resultados entre a primeira e a segunda faixa etária. De um total de doze informantes entrevistados, (i) seis informantes da primeira faixa (50\%) e seis informantes da segunda faixa etária (50\%) afirmaram que falam como o segundo áudio (não alteado); (iii) dois informantes (17\%) de cada uma das faixas etárias disseram que misturariam o modo de falar do primeiro e do segundo áudio; (iv) por último, quatro informantes (33\%) de cada uma das faixas etárias não perceberam o alteamento. Logo, as duas faixas tiveram números e percentuais iguais em relação à realização de alteamento, de não alteamento e de variação.

Por fim, em relação à escolaridade, nenhum informante afirmou que fala como o primeiro áudio (alteado). Sete informantes com ensino médio (58\%) e cinco informantes com ensino superior (42\%) afirmaram que não falam como o segundo áudio (não alteado). Já três informantes com ensino superior (25\%) e um informante com ensino médio (8\%) disseram que, ao falar a frase, misturariam o modo de falar do primeiro e do segundo áudios, ou seja, esses informantes parecem reconhecer a possibilidade de mais de uma forma de realização das palavras. Por último, quatro informantes do ensino médio e do ensino superior (33\%) não perceberam o alçamento no segundo áudio. Tal resultado confirma a afirmação de Botassini (2012), que diz que "os informantes de menos instrução são os que manifestam atitudes de rejeição, enquanto os mais escolarizados são menos preconceituosos".

A seguir, apresentam-se alguns depoimentos.
(4) "Eu falaria como o segundo porque não se fala t[i]cido né? Se fala t[e]cido. A c[o]stureira c[o]rtou o t[e]cido da m[i]nina no d[u]mingo, [i]nquanto seu [i]sposo J[u]ão c[o]nsertava a t[o]rneira e sua filha $\mathrm{M}[\mathrm{e}]$ lissa brincava no [i]stofado com uma b[u]neca" (Feminino).

(5) "Eu misturaria os dois. A c[o]stureira cortou o t[e]cido da m[i]nina no $\mathrm{d}[\mathrm{u}]$ mingo, [i]nquanto seu [i]sposo J[o]ão c[o]ns[e]rtava a t[o]rneira e sua filha M[e]lissa brincava no [e]stofado com uma b[o]neca" (Masculino).

- Pergunta 3: Quando você/o(a) senhor(a) escuta uma pessoa falando como no segundo trecho, o que poderia dizer a respeito dessa pessoa?

- ОвјETIvo: Fazer o informante emitir uma opinião em relação aos informantes que realizam as vogais médias não alteadas. Nessa pergunta, observa-se o teste de reação subjetiva, em que o respondente emite juízo em relação à personalidade das pessoas.

No que diz respeito ao gênero, tanto os informantes de gênero feminino quanto os de gênero masculino avaliaram positivamente o segundo áudio, considerando-o mais correto: onze mulheres (92\%) avaliaram positivamente o não alteamento das vogais pretônicas no segundo áudio; entre os homens, apenas cinco informantes (42\%) avaliaram positivamente o não alteamento, mas os oito demais, uma mulher (8\%) e sete homens (58\%) sequer perceberam a realização do alteamento.

Em relação à faixa etária, oito informantes (67\%) de cada uma das faixas etárias avaliaram positivamente o não alteamento do segundo áudio. Os quatro informantes restantes (33\%) de cada uma das faixas etárias não fizeram algum tipo de julgamento, pois não perceberam o alteamento. Percebe-se que não há diferenças, nessa amostra, na avaliação do alteamento entre as faixas etárias consideradas. 
Por fim, em relação à escolaridade, oito dos informantes detentores de ensino médio (67\%), bem como oito informantes com ensino superior completo (67\%), avaliaram positivamente o não alteamento, não havendo nenhum que o avaliasse negativamente. Os quatro informantes restantes (33\%) de cada nível de escolaridade não foram capazes de perceber o alteamento e, por isso, não o avaliaram.

(6) "Norma culta, né? Uma pessoa que estudou mais, que tem mais esclarecimento. Não só por isso também, desculpa, mas sim porque ela estaria lendo corretamente o que tá escrito" (Feminino/Faixa 1/Ensino Superior).

(7) "Que ela tem estudo" (Feminino/Faixa 1/Ensino Médio).

\section{Áudio 1:}

[e]stela trabalha como [e]mpr[e]gada $\mathrm{d}[\mathrm{o}]$ méstica. Ela lava as c[o]rtinas, limpa os [e]spelhos, lava as roupas [e]ncardidas. Além disso, [e]stela é uma boa c[o]mpanheira para idosos e c[o]zinha muito bem. Faz muito bem o seu s[e]rviço.

\section{- Pergunta 4: Se tivesse de apostar na profissão da pessoa que produz o} primeiro áudio, como a caracterizaria primeiramente? E no segundo, como a caracterizaria em termos profissionais? Ou você acha que a profissão não interfere?

- OвJETivo: Observar se o informante associa (i) o uso da variante não alteada a uma pessoa de profissão de prestígio/maior escolarização ou (ii) o uso da variante alteada a uma pessoa de profissão de menor prestígio social/baixa escolarização.
Analisando-se as respostas, observou-se que alguns informantes não elegeram a profissão para as pessoas do áudio - dezesseis informantes não avaliaram o áudio não alteado e dezoito informantes não avaliaram o áudio alteado, alegando que não é possível atribuir uma profissão à pessoa pela sua maneira de falar, de modo que tanto uma advogada quanto uma empregada doméstica podem falar como no segundo áudio (alteado). Já os informantes que elegeram profissões parecem avaliar negativamente o falante que produz a variante alteada. Independentemente do gênero, da faixa etária e da escolaridade, oito informantes (57\%) avaliaram a pronúncia do áudio não alteado e atribuíram ao falante uma profissão de maior prestígio social e de maior grau de escolarização - professora, advogada. Diferentemente, seis informantes (43\%) atribuíram uma profissão menos prestigiosa socialmente e de baixa escolaridade à pessoa que produz o alteamento - empregada doméstica, atendente e merendeira.

Entre os informantes que opinaram, observa-se que, ao analisarem o áudio não alteado (primeiro), não houve diferença na avaliação da profissão do falante devido a nenhum dos critérios sociolinguísticos utilizados. Em relação ao gênero, seis mulheres (42\%) disseram que a pessoa do primeiro áudio seria uma professora, enquanto uma (8\%) declarou que se tratava de uma advogada e seis mulheres (50\%) não elegeram uma profissão; entre os dois homens que opinaram, um (8\%) disse tratar-se de uma professora, enquanto outro (8\%) declarou que se tratava de uma atendente, mas os dez homens restantes (84\%) não atribuíram uma profissão ao falante do áudio. No que diz respeito à faixa etária, duas pessoas de primeira faixa etária (17\%) e quatro da segunda faixa etária (33\%) disseram que se tratava de uma professora, ao passo que um informante de primeira faixa etária (8\%) disse que era uma advogada e um respondente da segunda faixa etária (8\%) disse que era uma atendente. Entre os demais informantes, nove pessoas da primeira faixa etária (75\%) e sete da segunda faixa etária (59\%) não 
elegeram uma profissão para o falante do primeiro áudio. Por fim, em relação à escolaridade, três pessoas detentoras de nível médio de escolaridade (25\%) e outras três detentoras de nível superior (25\%) disseram que era uma professora; um informante detentor de ensino médio (8\%) afirmou que se tratava de uma atendente, enquanto (8\%) outro declarou que se tratava de uma advogada. Entre os demais, sete informantes do ensino médio (59\%) e nove do ensino superior (75\%) não quiseram opinar a respeito da profissão do falante do primeiro áudio.

Em relação à profissão do falante do áudio alteado (segundo), de acordo com o gênero, dos informantes que opinaram, três mulheres (25\%) disseram que o áudio seria de uma empregada doméstica, uma mulher (8\%) disse que seria uma atendente, uma mulher (8\%) disse que seria uma merendeira e nove mulheres (59\%) não atribuíram uma profissão ao falante do segundo áudio; apenas um homem (8\%) dispôs-se a avaliar como se tratando da fala de uma empregada doméstica, mas os onze homens (92\%) restantes não elegeram uma profissão para o falante. No que diz respeito à faixa etária, um informante da primeira faixa $(8 \%)$ e três da segunda (25\%) disseram que era uma empregada doméstica, um informante da primeira (8\%) afirmou que era uma merendeira e um da segunda faixa $(8 \%)$ afirmou que seria uma atendente. No entanto, dez informantes da primeira faixa etária (84\%) e oito da segunda faixa (67\%) não opinaram na profissão do falante. Em relação à escolaridade, três informantes detentores de ensino médio (25\%) e um informante detentor de ensino superior (8\%) disseram que a pessoa era uma empregada doméstica; um informante de ensino superior (8\%) afirmou que era uma atendente e um informante de ensino médio ( $8 \%$ ) disse que se tratava de uma merendeira, mas oito informantes do ensino médio (67\%) e dez informantes do ensino superior (84\%) não quiseram atribuir uma profissão à pessoa do segundo áudio.

Portanto, em relação aos informantes que opinaram na profissão do falante do áudio, verifica-se que os informantes: (i) tendem a eleger uma profissão mais prestigiosa a pessoa do áudio que utiliza as vogais médias fechadas e (ii) tendem a eleger uma profissão menos prestigiosa a pessoa do áudio que realiza o alteamento.

Um fato interessante que se observou durante a entrevista foi que, quando se pedia que o informante dissesse a profissão da pessoa do primeiro áudio (não alteado), elegia-se uma profissão de prestígio (professora, advogada); no entanto, em relação ao segundo áudio (alteado), o informante dizia que não poderia responder, pois a maneira de falar não se relacionava com a profissão do indivíduo. Logo, observou-se que o informante não queria se comprometer em sua resposta, talvez porque estivesse preocupado em ser "politicamente correto". Abaixo, há alguns exemplos de depoimentos:

(8) "Não sei responder isso. Acho que ela pode ter uma profissão qualquer. Eu acho que a profissão é uma consequência. Eu não acho que seria por causa da profissão" (Feminino/Faixa 1/Ensino Médio).

(9) "Não tem nada a ver. A pessoa pode ser do nível superior tanto no primeiro quanto no segundo. Na verdade, ela só tá variando a forma de falar a vogal. Ela não deixa de falar com correção de uma forma para outra" (Masculino/ Faixa 1/Ensino Superior).

\section{Áudio 1:}

$\mathrm{D}[\mathrm{o}]$ mingos é um $\mathrm{m}[\mathrm{e}]$ nino muito [e]sperto. Ele tinha $\mathrm{p}[\mathrm{e}] \mathrm{rdido}$ seu brinquedo, mas seu pai J[o]sé o [e]nc[o]ntrou [e]mbaixo

da [e]scada. $\mathrm{D}[\mathrm{o}]$ mingos c $[0]$ ntinuou pr[o]curando. 0 pai só [e]ntregou o

brinquedo a noite e em s[e]guida mandou-o $\mathrm{d}[\mathrm{o}]$ rmir.

\author{
Áudio 2: \\ $\mathrm{D}[\mathrm{u}]$ mingos é um $\mathrm{m}[\mathrm{i}]$ nino muito [i]sperto. \\ Ele tinha p[i]rdido seu brinquedo, mas \\ seu pai J[u]sé o [i]nc[u]ntrou [i]mbaixo \\ da [i]scada. D[u]mingos c $[\mathrm{u}]$ ntinuou \\ pr[u]curando. O pai só [i]ntregou o \\ brinquedo a noite e em s[i]guida mandou-o \\ $\mathrm{d}[\mathrm{u}]$ rmir.
}


- Pergunta 5: Imagine uma pessoa relatando a você/ao senhor(a) a condição do menino Domingos, em dois contextos sociais diferentes: numa reunião de empresa e numa reunião familiar. Numa reunião de trabalho, você o(a) senhor(a) acha que a fala seria igual à do primeiro áudio, à do segundo ou com a mistura dos dois áudios? $\mathrm{E}$ numa reunião de família?

- ОвJETIVo: observar se o informante acha que a realização do alteamento está relacionada com o grau de formalidade da situação ou se o informante tem consciência de que o alteamento ocorre tanto em situações formais quanto informais.

Ao analisar as respostas dos informantes em relação ao contexto da reunião de trabalho, observam-se os seguintes resultados: (i) nove mulheres $(75 \%)$ e seis homens (50\%) disseram que a pessoa falaria como o primeiro áudio (não alteado), ao passo que quatro homens (38\%) e duas mulheres (17\%) afirmaram que a pessoa utilizaria uma mescla de palavras do primeiro áudio (não alteado) e palavras do segundo áudio (alteado), enquanto uma mulher (8\%) e dois homens (17\%) não identificaram a diferença entre os áudios; (ii) sete informantes da primeira faixa (59\%) e oito informantes da segunda faixa etária (67\%) disseram que, numa reunião de trabalho, a pessoa falaria como no áudio não alteado, enquanto quatro informantes da primeira faixa (33\%) e dois da segunda faixa etária (17\%) disseram que seriam misturadas as maneiras de falar do primeiro e do segundo áudios, mas um informante da primeira faixa (8\%) e dois da segunda faixa etária (16\%); (iii) sete informantes detentores de ensino médio (59\%) e oito informantes de ensino superior (67\%) afirmaram que falariam como no áudio não alteado, mas quatro informantes de ensino médio (33\%) e outros dois de ensino superior (17\%) declararam que seriam mescladas as maneiras de falar do primeiro e do segundo áudio, enquanto um informante do ensino médio (8\%) e dois informantes do ensino superior (16\%) não observaram a diferença entre os áudios.

Já ao perguntar como a pessoa falaria em uma reunião familiar observamse respostas diferentes das que foram dadas em relação ao contexto de reunião de trabalho: (i) seis informantes do gênero feminino (50\%) e nove do gênero masculino (75\%) afirmaram que na reunião familiar a pessoa falaria como o áudio alteado, duas mulheres (17\%) disseram que a pessoa poderia falar como o áudio não alteado, três mulheres (25\%) e um homem (8\%) afirmaram que se misturariam as maneiras de falar do primeiro e do segundo áudios, mas dois homens (17\%) e uma mulher (8\%) não observaram a diferença entre os áudios; (ii) sete informantes da primeira faixa (58\%) e oito da segunda faixa etária (67\%) disseram que a pessoa falaria como o segundo áudio (não alteado), dois informantes da primeira faixa (17\%) disseram que a pessoa falaria como o primeiro áudio (não alteado), dois informantes da primeira faixa (17\%) e dois da segunda faixa (17\%) disseram que se misturaria a maneira de falar dos dois áudios, enquanto um informante da primeira faixa (8\%) e dois da segunda (16\%) não verificaram a diferença entre os áudios; (iii) seis informantes detentores de ensino médio $(50 \%)$ e nove detentores de ensino superior $(75 \%)$ afirmaram que a pessoa falaria como o áudio alteado, dois informantes de ensino médio (17\%) disseram que a pessoa falaria como o primeiro áudio (não alteado), quatro informantes de ensino médio (33\%) e um de ensino superior (8\%) disseram acreditar que o falante poderia misturar as duas maneiras de falar, mas dois informantes de ensino superior (17\%) não identificaram a diferença entre os áudios.

Portanto, observa-se que os respondentes privilegiaram a variante não alteada para o contexto formal de reunião de trabalho, ao passo que reconheceram a possibilidade de realização da variante alteada na reunião familiar. Observa-se, ainda, que alguns respondentes acreditam que o 
indivíduo pode variar entre as formas alteadas e não alteadas em ambas as situações comunicativas.

- Pergunta 6: Para você/o(a) senhor(a), essas diferentes realizações interferem no entendimento da frase? Por exemplo, você/o(a) senhor(a) entende se eu falar $\mathrm{m} / \mathrm{i} / \mathrm{nino}$ em vez de $\mathrm{m} / \mathrm{e} / \mathrm{nino}, \mathrm{c} / \mathrm{u} / \mathrm{stura}$ em vez de c/o/stura, acad/i/mia em vez de acad/e/mia. Por quê?

- OвJETIVo: Fazer o informante refletir se o alteamento das vogais pretônicas interfere no entendimento da informação. Pela resposta, é possível observar se há algum preconceito do informante em relação às pessoas que realizam as vogais alteadas.

Analisando-se o gênero, a faixa etária e o grau de escolaridade, observou-se que: (i) onze mulheres (92\%) e onze homens (92\%) disseram que as diferentes realizações não interferem no entendimento da frase, mas um homem (8\%) e uma mulher (8\%) disseram que há interferência de significado; (ii) dez informantes da primeira faixa (83\%) e doze da segunda faixa etária (100\%) acreditam que essas diferentes realizações não interferem no entendimento de um enunciado, mas dois informantes da primeira faixa etária (17\%) acreditam que não é possível entender frases ou palavras se estas se realizarem alteadas; (iii) onze informantes detentores de ensino médio (92\%) e onze informantes de ensino superior (92\%) dizem que as diferentes realizações não atrapalham no entendimento do significado, mas um informante de ensino médio (8\%) e um informante de ensino superior (8\%) acreditam na interferência.

Independentemente do gênero, da faixa etária e do grau de escolaridade, a maioria dos informantes defendeu que o alteamento não interfere no entendimento da frase. Entretanto, muitos informantes disseram que o alteamento é um erro e que, se ouvissem uma pessoa realizando tal construção, iriam rir. Por isso, é possível afirmar que esses informantes, ao considerarem o alteamento como "erro", tendem a avaliar negativamente o usuário da variante alteada.

(10) “Eu até entendo, mas vou rir um pouquinho. Dá para entender, mas eu vou achar engraçado porque não é o meu modo de falar” (Masculino/Faixa 2/ Ensino Médio).

(11) “Eu entendo, só que você sabe que está errado né? Não vai influenciar, mas se você puder corrigir" (Feminino/Faixa 1/Ensino Médio).

A partir da entrevista, foi possível observar que o alteamento das vogais médias pretônicas aparenta ser avaliado negativamente no Rio de Janeiro, uma vez que, ao analisar as respostas dos informantes, é possível concluir que os informantes: (i) dizem que não realizam o alteamento, pois acreditam que é um erro na língua portuguesa; (ii) atribuem às pessoas que realizam o alteamento uma profissão de baixo prestígio, uma vez que possuem pouca escolaridade; (iii) afirmam que o alteamento pode ocorrer na reunião familiar, pois nessa situação o indivíduo não está sendo avaliado; e (iv) defendem que o alçamento das vogais pretônicas não compromete o entendimento da frase, mas dizem que é errado usar as variantes altas [i] e [u].

\subsubsection{Questionário fonético-fonológico}

O objetivo do questionário foi verificar, depois do teste de leitura e do questionário, se o informante monitora mais a sua fala em relação ao alteamento das vogais médias pretônicas por já identificar o objeto de análise do estudo. Dentre 25 questões, apenas 13 foram efetivamente utilizadas como instrumento para o presente trabalho, visto serem as únicas a propiciarem respostas com médias pretônicas. 0 questionário fonético- 
fonológico baseou-se no modelo proposto pelo Atlas Linguístico Brasileiro (ALiB), sendo selecionadas as questões que tinham como resposta palavras com vogal média e sendo criadas apenas questões para abarcar uma palavra com média posterior travada por sibilante /S/ e uma palavra com média posterior travada por nasal /N/.

$\mathrm{Na}$ análise, estabeleceu-se um contínuo em relação ao número de palavras alçadas no questionário. Considerou-se que: (a) as pessoas que realizaram o alteamento até seis palavras controlaram o fenômeno, enquanto (b) as pessoas que altearam as vogais pretônicas mais de seis vezes não controlaram.

\section{Figura 1}

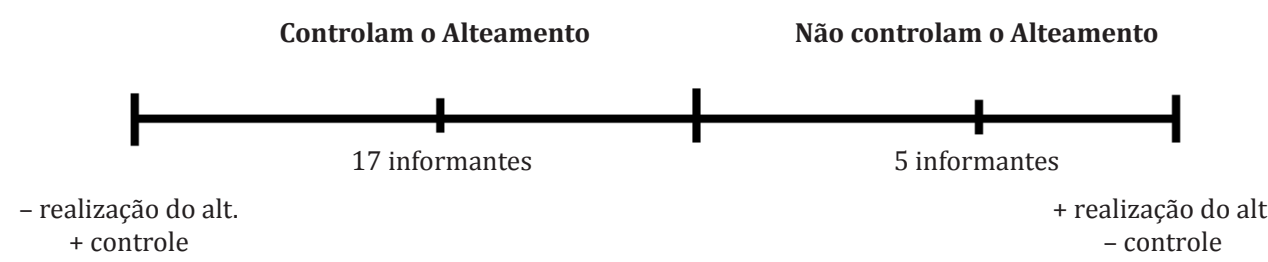

Conforme se pode observar, dezessete informantes controlaram mais o alteamento. Apenas cinco informantes não controlaram. No entanto, verificou-se que muitas vezes o informante forçava a realização da média pretônica com /e/ e /o/, isto é, não era uma realização natural do dia a dia do informante. Houve um caso em que o informante não realizou nenhuma resposta com a vogal alteada, porém na leitura do texto e durante a entrevista se pôde observar que alçou diversas vezes várias palavras. Esse resultado é uma evidência de que os falantes parecem avaliar negativamente o fenômeno do alteamento, pois se preocuparam em não produzir a variante alteada.

\section{Considerações finais}

Com base nas duas análises experimentais, pôde-se observar que, ao contrário do que atesta a vasta literatura existente sobre o alteamento pretônico, o processo desperta a atenção dos respondentes e, mais do que isso, desperta uma avaliação negativa: alguns informantes estudados afirmam que as pessoas que procedem ao alteamento estão cometendo um "erro" e que possuem menor grau de escolaridade. Além disso, os respondentes selecionados em ambos os estudos demonstram não ter consciência da norma que manifestam em relação ao alteamento pretônico, uma vez que há diferença entre o que os usuários da língua dizem produzir e o que efetivamente produzem nas mais variadas situações de comunicação cotidiana e, mesmo, nas diferentes técnicas de análise aqui propostas.

Nos termos de Labov (2008) e a partir dos testes de Crenças e Atitudes aplicados, é possível afirmar que o alteamento está entre indicador e marcador. Pode ser classificado como um indicador, uma vez que não é marcado socialmente, ou seja, os falantes não têm consciência de sua realização e, muito menos, de que eles mesmos o realizam. No entanto, pode também ser classificado como marcador, uma vez que, embora esteja abaixo do nível de consciência do informante, o falante tende a produzir respostas regulares de avaliação, geralmente negativa, em testes de reação subjetiva acerca do fenômeno.

No que diz respeito à primeira análise, a etapa de produção linguística demonstrou que a especialização semântica é bastante sutil e que os respondentes, ao menos na situação de exposição a um questionário fonético-fonológico, tendem a se preocupar com a "pronúncia correta" dos itens quando estão sendo entrevistados e gravados. No entanto, algumas informações interessantes puderam ser depreendidas a respeito do fenômeno, como o fato de ser efetivamente motivado pela "intimidade" do respondente 
para com o item: o vocábulo fogão, para designar o aparelho doméstico utilizado para cozinhar, é quase categoricamente alteado na amostra, dada a frequência de seu uso, enquanto o vocábulo cobertura, para designar a calda que se adiciona sobre um bolo, é mais frequentemente realizado por meio da variante médio-alta, em virtude de a "intimidade" com o item se estabelecer apenas entre um grupo específico de falantes; o vocábulo seguro, para designar a proteção veicular, é mais constantemente alteado, por ser um serviço a que todos os proprietários de automóveis (e outros produtos "de valor") costumam recorrer, enquanto o vocábulo segurança, para designar o profissional responsável por vigiar propriedades mais abastadas, é mais frequentemente realizado através da variante médio-alta, visto que se trata de um serviço oferecido apenas a pessoas com maiores posses.

A etapa de percepção, por sua vez, indicou que, mesmo os casos mais "cristalizados", tais como fogão e sentido, não são tão constantemente especializados, visto que alguns respondentes insistem em contrariar o que produzem por meio de uma norma que não lhes pertence. Por outro lado, a hipótese experimental de que o alteamento se presta à expressão de significados menos valorizados socialmente pôde ser confirmada por algumas constatações, como a de que o alteamento pretônico (i) em serviço faz com que o item se refira não mais ao trabalho que se realiza, mas ao funcionalismo público; (ii) em perua faz com que se refira não mais ao veículo, mas a alguma mulher que se veste de maneira espalhafatosa; (iii) em sentido faz com que o vocábulo se refira não mais à ordem militar, mas à ideia de decepção ou de direção.

No que tange à segunda análise, a entrevista demonstrou que os informantes (a) percebem o alteamento das vogais médias pretônicas; (b) ao julgarem as pessoas que produzem o alteamento, afirmam que não realizam o fenômeno; (c) atribuem o alteamento a um grupo específico de usuários da língua, geralmente indicando que o uso da variante alteada está associado às pessoas de profissão menos prestigiada, com baixa escolaridade, ao passo que o não alteamento é associado às pessoas com uma profissão prestigiada, com alta escolaridade; (d) parecem apresentar estigma quando as vogais pretônicas se realizaram pela variante alteada, tendo em vista a avaliação positiva do não alteamento; (e) disseram que o alteamento ocorre em uma situação mais informal; (f) quanto a gênero, faixa etária e grau de escolaridade, comportam-se de maneira diferente em cada pergunta; e, por fim, que (g) as mulheres se mostraram mais sensíveis em relação ao alteamento.

Tanto no questionário quanto na leitura, observou-se que todos os informantes realizaram o alteamento das vogais pretônicas. No entanto, pôde-se observar que, após as perguntas de percepção e avaliação, os informantes controlaram mais a própria produção do alteamento das vogais pretônicas, às vezes sequer procedendo a uma "fala natural", em virtude de forçarem a realização que julgavam mais valorizada.

\section{Referências}

ABRAÇADO, Jussara; KENEDY, Eduardo. Transitividade: traço a traço. Niterói: EdUFF, 2014.

AGUILERA, Vanderci de Andrade. Crenças e Atitudes Linguísticas: quem fala a língua brasileira? In: RONCARATI, Cláudia; ABRAÇADO, Jussara (Org.). Português Brasileiro II: contato linguístico, heterogeneidade e história. Niterói, Rio de Janeiro: EdUFF, 2008, p. 311-333.

AVELHEDA, Anna Carolina da Costa. O alteamento das vogais médias pretônicas no município de Nova Iguaçu: análises sociolinguística e acústica. Dissertação (Mestrado) - Programa de Pós-Graduação em Letras Vernáculas, Universidade Federal do Rio de Janeiro, Rio de Janeiro, 2013.

BOTASSINI, Jacqueline Ortelan Maia. Crenças e Atitudes Linguísticas: um estudo dos róticos em coda silábica. In: ALTINO, Fabiane (Org.). Múltiplos olhares sobre a Diversidade Linguística: nos caminhos de Vanderci de Andrade Aguilera. Londrina: MidioGraf, 2012. 
Crenças e Atitudes: um estudo dos róticos em coda silábica no Norte do Paraná. Tese (Doutorado em Estudos da Linguagem) - Centro de Letras e Ciências Humanas. Programa de Pós-Graduação em Estudos da Linguagem, Universidade Estadual de Londrina, Londrina, 2013.

DIAS, Luiz Antônio Xavier. Crenças e Atitudes Linguísticas no uso dos Róticos de Professores e Professorandos de Jacarezinho - PR. Entrepalavras, ano 4, v. 4, n. 2, p. 90-104, jul./dez. 2014.

LABOV, William. Padrões Sociolinguísticos. Tradução de Marcos Bagno, Maㅗ Marta Pereira Scherre e Caroline R. Cardoso. São Paulo: Parábola Editorial, 2008.

LAMBERT, William W.; LAMBERT, Wallace E. Psicologia Social. 4. ed. Tradução de Dante Moreira Leite. Rio de Janeiro: Zahar, 1975.

LÓPEZ MORALES, H. Estratificación sociolectal frente a diglosia em el Caribe Hispánico. L. E. A. V, 1983. p. 205-224.

MACHADO VIEIRA, Marcia dos Santos; ESTEVES, Giselle Aparecida Toledo. Metodologia de avaliação subjetiva de usos linguísticos em variação. In: LOPES, Celia; REICH, Uli. Romania. Variação Linguística em Megalópoles Latino-Americanas, 39. 2009. p. 237-266,.

OLIVEIRA, Marco Antônio de. The neogrammarian controversy revisited. International Journal of the Sociology of Language, v. 89, n. 1, p. 93-105, 1991.

OUSHIRO, Livia. Identidade na Pluralidade: Avaliação, produção e percepção linguística na cidade de São Paulo. Tese (Doutorado em Letras) - Faculdade de Filosofia, Letras e Ciências Humanas, Universidade de São Paulo, 2015.

VIEGAS, Maria do Carmo. Alçamento de vogais pretônicas: uma abordagem sociolinguística. 1987. 231 fl. Dissertação (Mestrado em Linguística) - Faculdade de Letras, Universidade Federal de Minas Gerais, Belo Horizonte. 1987.

O alçamento de vogais médias pretônicas e os itens lexicais. 2001. $283 \mathrm{fl}$. Tese (Doutorado em Estudos Linguísticos) - Faculdade de Letras, Universidade Federal de Minas Gerais, Belo Horizonte, 2001.

WEINREICH, Uriel; LABOV, William; HERZOG, Marvin I. Fundamentos empíricos para uma Teoria da Mudança Linguística. Tradução de Marcos Bagno. São Paulo: Parábola Editorial, 2006. 